\title{
SAMPLE RECOVERY RATIOS AND SAMPLER PENETRATION RESISTANCE IN TUBE SAMPLING FOR NIIGATA SAND
}

\author{
Takaharu Shogaki ${ }^{i)}$, Yoshihito Nakano ${ }^{\text {ii) }}$ and Azuma Shibata ${ }^{\text {ii) }}$
}

\begin{abstract}
In this paper, sample recovery ratios, fluid pressure and sampler penetration resistance in tube sampling are discussed. The samplers were taken by two types of hydraulic piston samplers, one a two-chambered sampler with inner diameters of $45 \mathrm{~mm}$ and $50 \mathrm{~mm}$, and the second a one-chambered sampler having a $70 \mathrm{~mm}$ diameter. The second type is the one commonly used in Japan and which was also used at the Meike Elementary School, the JGS-1989 investigation site. These samplers are here after referred to as the 45D, 50D and 70S samplers. The mean value of the sample recovery ratios from the $45 \mathrm{D}$ and 50D samplers was $93 \%$ greater than that of the $70 \mathrm{~S}$ sampler. This value remained independent of the sands having $N=3 \sim 54$ from the standard penetration test. Guidelines for estimating the pump fluid pressure for tube sampling of sand, sampler and drilling equipment penetration resistance forces and the relationship between the sample recovery ratios and the drilling mud densities, etc., were established for Niigata sand. The end results contribute to a safer and more reliable sampling method.
\end{abstract}

Key words: CPT, mud density, penetration pressure, sample recovery ratio, sand, small diameter sampler, SPT, undisturbed tube sampling (IGC: C5/C6)

\section{INTRODUCTION}

The soil sampling committee of the Japanese Society for Soil Mechanics and Geotechnical Engineering conducted systematic sampling in Niigata city (JGS-1989 investigation) in order to establish a tube sampling method for natural sand deposits and an evaluation technique for the sample quality obtained (Japanese Geotechnical Society, 1989). In this sampling, $33 \%$ of the samples were $0 \%$ of the sample recovery ratios $\left(R_{\mathrm{r}}\right)$, which is defined in an equation as the ratio of the length of the sample before withdrawal over the penetration depth during sampling. It was thought that the reason for the low $R_{\mathrm{r}}$ values was medium sand, in which $50 \%$ of the grain size is about $0.3 \mathrm{~mm}$, the percentage of grain size smaller than $0.075 \mathrm{~mm}$ is small and the uniformity coefficient of the sand is about 2 (Japanese Geotechnical Society, 1989).

The undisturbed samples for these sands are usually obtained by an in-situ freezing method, since tube sampling is very difficult. However, if in-situ dynamic strength properties can be estimated from laboratory tests for undisturbed samples using a tube sampler, the geotechnical investigation and design accuracy can be improved, therefore greatly reducing costs. For sand sampling using a tube sampler, lack of penetration resistance to the sampler affects the $R_{\mathrm{r}}$ and sample quality. The penetration force of the sampler depends upon the soil strength. However, there have been no guidelines estab- lished for the fluid pressure and penetration resistance forces. If this information can be obtained from the $N$ value of the Standard Penetration Test (SPT), and/or the cone index $\left(q_{\mathrm{c}}\right)$ of the Cone Penetration Test (CPT) before sampling, then estimating the resistance forces for sampler and drilling equipment penetration can be done, resulting in a safer, more reliable sampling method.

Shogaki (1997) developed a new sampler called a 45D sampler, which has a $45 \mathrm{~mm}$ inner diameter and a twochambered hydraulic piston and its applicability was tested through unconfined compression tests for six different sites in Japan (Shogaki and Tokuda, 2001). It was confirmed from Shogaki and Tokuda (2001) that for Japanese clay deposits having unconfined compressive strength $\left(q_{\mathrm{u}}\right)$ ranging from $23 \mathrm{kPa}$ to $604 \mathrm{kPa}$, the $q_{\mathrm{u}}$ and the secant of modulus $\left(E_{50}\right)$ for samples obtained from this sampler were between $(20 \sim 70) \%$ and $(30 \sim 90) \%$ greater than those of the $75 \mathrm{~mm}$ samplers normally used in Japan, one of which is a non-rotary, thin-walled, single tube type with a fixed piston and the other a rotary, double-tube sampler.

In this study, the applicability of the 45D sampler for Niigata sand, and guidelines for measuring pump fluid pressure and sampler penetration resistance in tube sampling of sand deposits are discussed. The samples were taken by a 45D sampler, a 50D sampler and a $70 \mathrm{~mm}$ sampler (70S sampler).

The $R_{\mathrm{r}}$ values from the 45D and 50D samplers were

i) Associate Professor, National Defense Academy, 1-10-20 Hashirimizu, Yokosuka 239-8686, Japan.

ii) Geotechnical Engineer, Kowa Co., Ltd., 6-1 Shinkou-cho, Niigata 950-8565, Japan.

Manuscript was received for review on May 11, 2001.

Written discussions on this paper should be submitted before May 1, 2003 to the Japanese Geotechnical Society, Sugayama Bldg. 4F, Kanda Awaji-cho 2-23, Chiyoda-ku, Tokyo 101-0063, Japan. Upon request the closing date may be extended one month. 


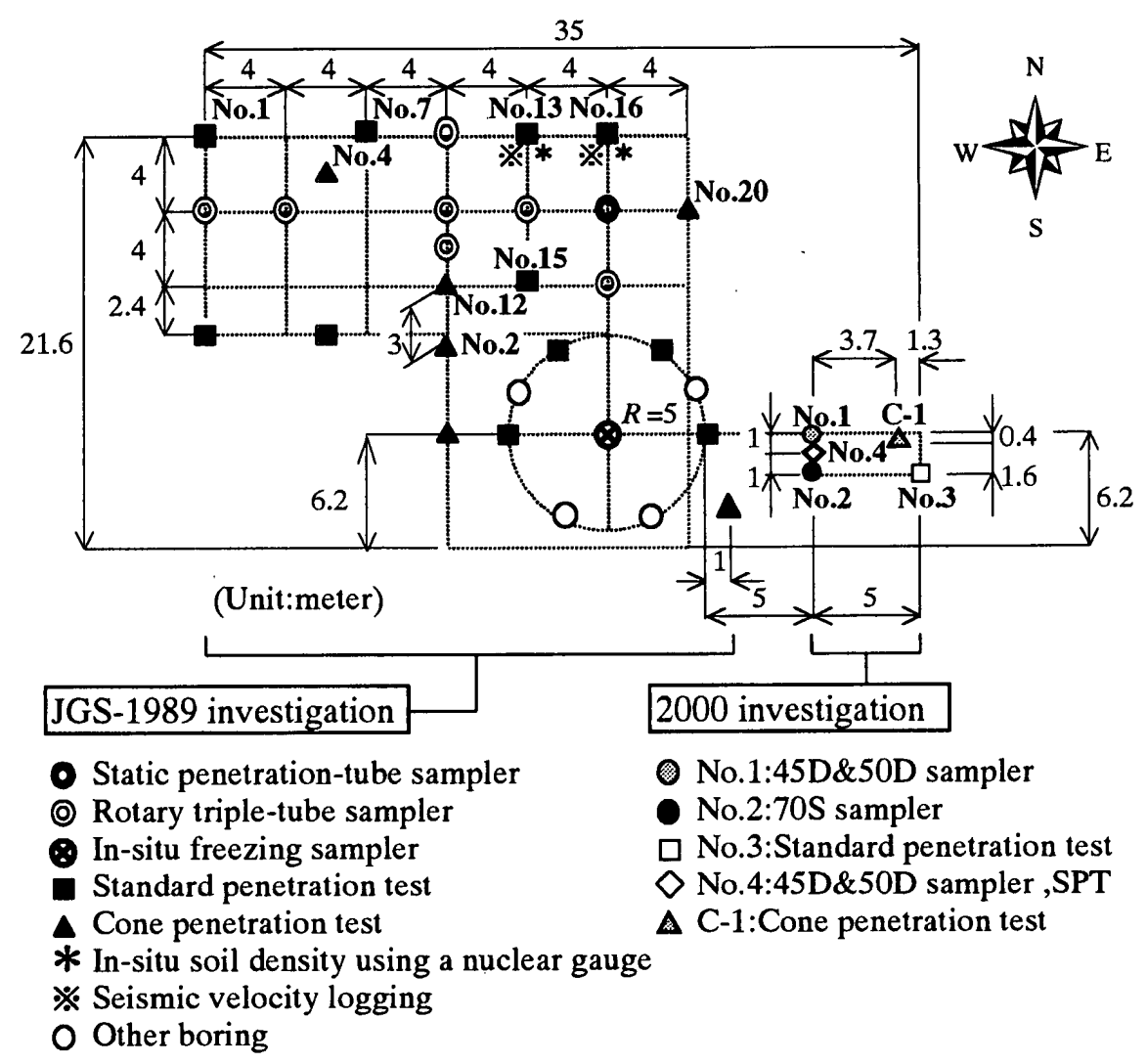

Fig. 1. Layout of the geotechnical investigation sites

greater than those of the 70S sampler and independent of the sands having $N=3 \sim 54$ from the SPT. Valuable information, such as the relationships between the $N$-values and the penetration pressure of the sampling tube, the $R_{\mathrm{r}}$ and the drilling mud density, etc., can be obtained by the method used in this study.

\section{SOIL PROFILE OF SAMPLING SITE}

Figure 1 shows the layout of the geotechnical investigation site, including the JGS-1989 investigation area. This paper's authors did the tube sampling, SPT and CPT in a $5 \mathrm{~m} \times 2 \mathrm{~m}$ area on the eastern side of the JGS-1989 investigation area. The $N$ and $q_{\mathrm{c}}$ values, including those of the JGS-1989 investigation, are plotted against the depth $(z)$ in Fig. 2. The CPT were performed in accordance with the Japanese Geotechnical Standard for electric cone penetration test (JGS 1435-1995). Based on the $N$ and the $q_{\mathrm{c}}$ values, it was determined that the layer at a depth of 2 $\sim 7 \mathrm{~m}$ was a sand hill and the lower sand layer at a depth greater than $7 \mathrm{~m}$ had been deposited by river water. The $N$ and $q_{\text {c }}$ values increase with depth and the scatter of these values at the same depth in an area about $35 \mathrm{~m} \times$ $22 \mathrm{~m}$ are $N=10 \sim 15$ and $q_{\mathrm{c}}=(3 \sim 12) \mathrm{MPa}$. Therefore, it can be judged that the geotechnical properties at equal depths throughout this area are almost similar. Figure 3 shows the relationship between the $N$ and $q_{\mathrm{c}}$ values. The $q_{\mathrm{c}}$ values are obtained from one of the mean depths of the measured $N$-value and compared with the closest borehole. The straight line, $q_{\mathrm{c}}=0.613 \mathrm{~N}$ (in $\mathrm{MPa}$ ) as shown in
Fig. 3, is a regression line obtained from the least square method. The correlation coefficient $(r)$ of the regression equation is 0.916 and it is a high value.

\section{SAMPLERS USED AND THE BORER SET-UP}

A sketch of the samplers used in this study is shown in Fig. 4 and their specifications are summarized in Table 1. The 45D and 50D samplers can be used in the same borehole with SPT, since the greatest outside diameter of these samplers is $60 \mathrm{~mm}$, as shown in Table 1. The penetration forces of the 45D and 50D samplers are about twice as powerful as that of the single-chambered hydraulic piston sampler of the same diameter. Trimming-down of the specimen is not necessary in the 45D and 50D samplers if the $50 \mathrm{~mm}$ diameter specimen commonly used in Japan is used for the strength test. On the other hand, a $110 \mathrm{~mm}$ borehole diameter is required for the 70 S sampler.

Both depth and time of penetration were determined by measuring both the wire movement and the air volume increase in the air cylinder from start to finish time of penetration for the 45D, 50D and 70S samplers respectively, as shown in Fig. 4. Figure 5 shows a sketch of the borer set-up. To determine the penetration resistance and safety factors for sand sampling of $N \fallingdotseq 50$ at $z=-12 \mathrm{~m}$, eight concrete blocks $1 \mathrm{~m}$ in height, $1 \mathrm{~m}$ in width and $0.5 \mathrm{~m}$ in length were placed underneath the frame of the drilling machine and fixed to it with two $\mathrm{H}$-shaped steel supports, wires and chain blocks. In this borer set-up, the 


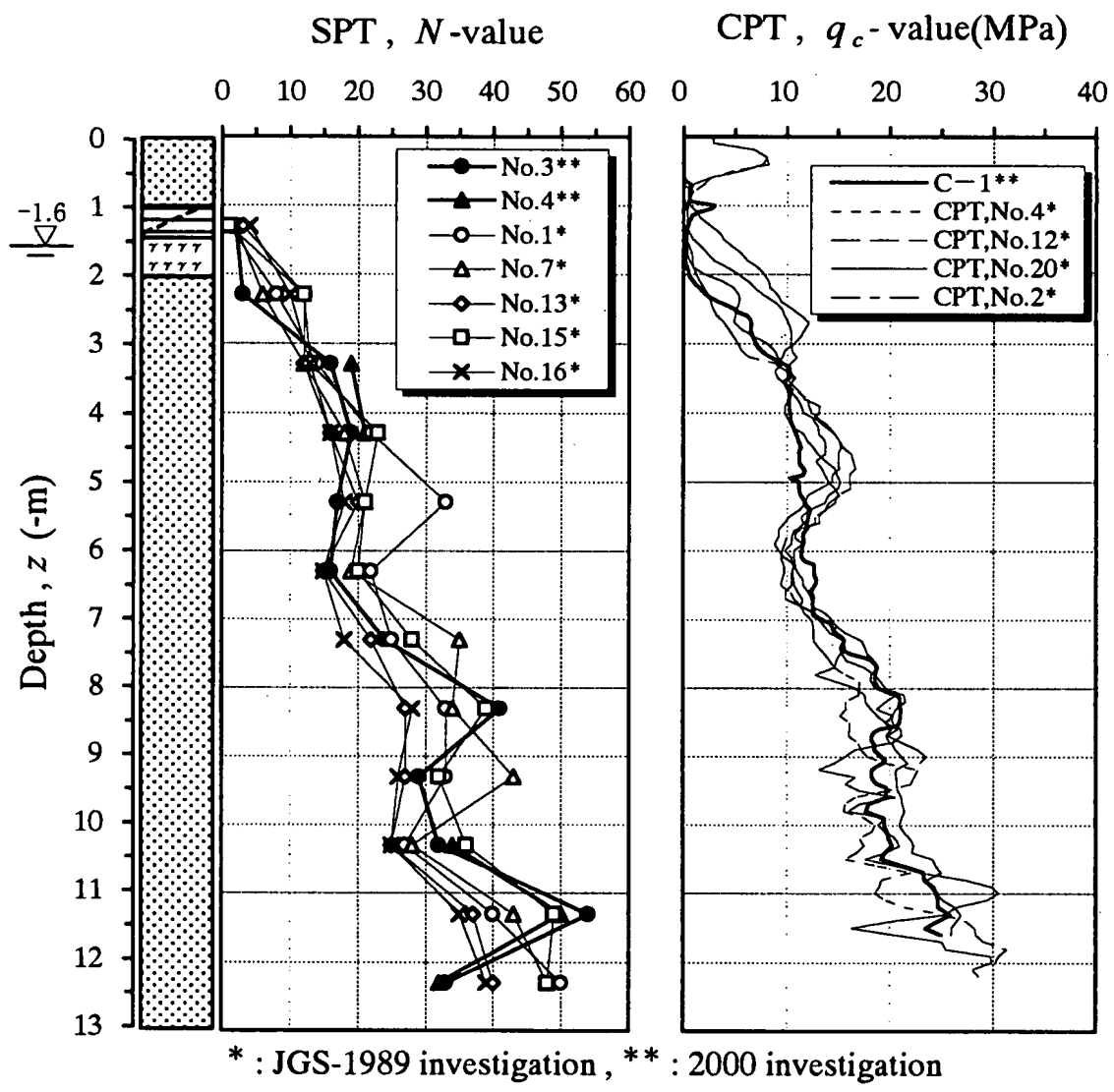

Fig. 2. Test results of SPT and CPT against the depths

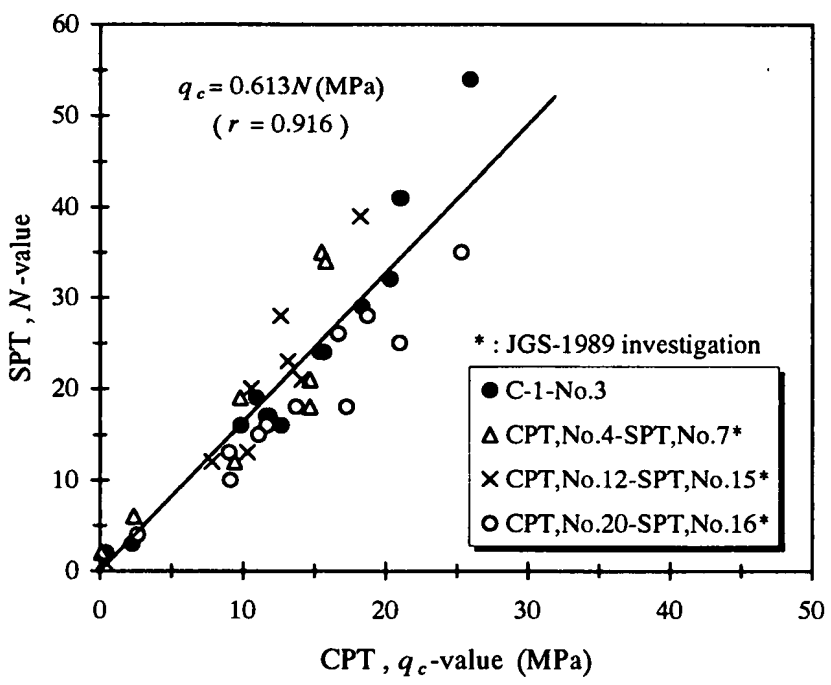

Fig. 3. Relationship between $N$ and $q_{\mathrm{c}}$ values

maximum displacement of the central part of the $\mathrm{H}$ shaped steel is calculated as $1.5 \mathrm{~cm}$ for a load of $98 \mathrm{kN}$ using $21 \times 10^{5} \mathrm{MPa}$ of the secant of modulus for $\mathrm{H}$-shaped steel.

\section{SAND SAMPLING}

The sand sampling using 45D, 50D and 70S samplers and SPT were done by the same engineer using the same
Table 1. Specifications of samplers used

\begin{tabular}{l|c|c|c}
\hline & $45 \mathrm{D}$ & $50 \mathrm{D}$ & $70 \mathrm{~S}$ \\
\hline Length of sampler $(\mathrm{mm})$ & 1340 & 1680 & 1165 \\
\hline Weight of sampler $(\mathrm{kg})$ & 10.6 & 12.8 & 21.4 \\
\hline Greatest outside diameter of sampler $(\mathrm{mm})$ & 60 & 60 & 90 \\
\hline Length of tube $(\mathrm{mm})$ & 600 & 800 & 950 \\
\hline Greatest outside diameter of tube, $D_{2}(\mathrm{~mm})$ & 52 & 56 & 76 \\
\hline Inside diameter of tube, $D_{1}(\mathrm{~mm})$ & 48 & 50 & 70 \\
\hline Thickness of tube $(\mathrm{mm})$ & 2 & 3 & 3 \\
\hline Edge taper angle $\left({ }^{\circ}\right)$ & 5.4 & 6.6 & 31.0 \\
\hline Thickness of edge $(\mathrm{mm})$ & 0.2 & 0.2 & 0.2 \\
\hline Inside clearance $(\mathrm{mm})$ & 0 & 0 & 0 \\
\hline Area ratio, $C_{\mathrm{a}}(\%)$ & 17 & 25 & 18 \\
\hline Maximum sample length $(\mathrm{mm})$ & 535 & 735 & 796 \\
\hline
\end{tabular}

$C_{\mathrm{a}}=\frac{D_{2}^{2}-D_{1}^{2}}{D_{1}^{2}} \times 100(\%)$

drilling machine, pump, etc., in order to reduce the possibility of human error. The number of samples were 9, 5 and 11 for 45D, 50D and 70S respectively and the relationship between the borehole number and depths is shown in Fig. 6 as plots including $R_{\mathrm{r}}$ and depths. The casing point was kept at the bottom of the borehole during 
each sampling.

There were misgivings that the sample inside the tube might collapse during the raising of the sampling tube after penetration, since the percentage of grain size smaller than $0.075 \mathrm{~mm}$ is about $1 \%$ and the uniformity coefficient is about 2 for Niigata sand. In fact, sand sample collapse had been reported in the JGS-1989 investigation. Therefore, a sump for mud was put around the casing tube as a counter measure and the sample was backed with porous stone in the sump, as shown in Fig. 7. The cutting edges

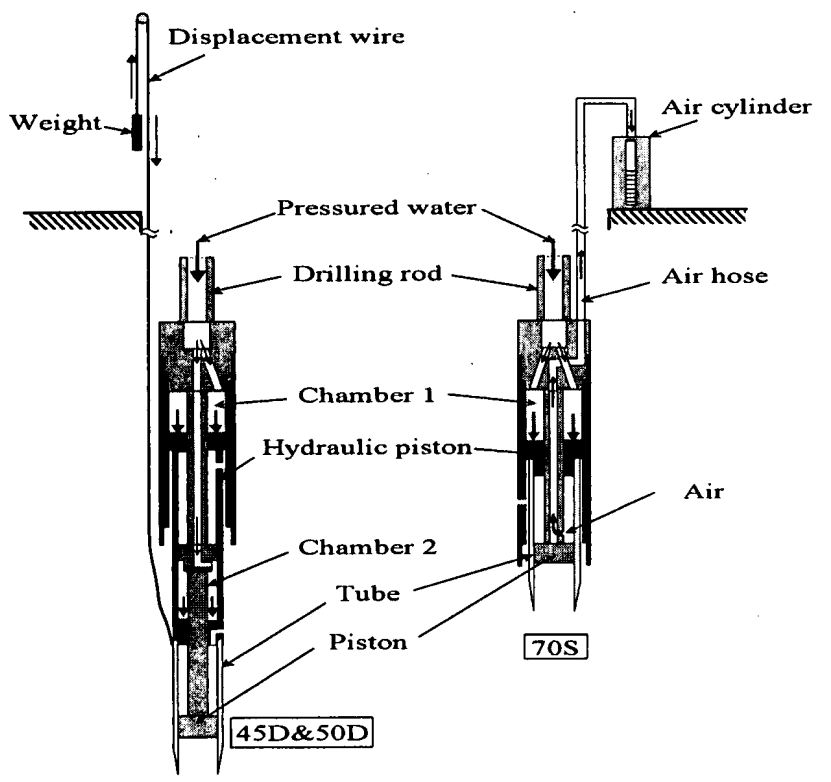

Fig. 4. A sketch of the samplers used and the measuring method for the penetration depths of the sampling tubes did not suffer any damage during all sampling.

\section{EFFECTS OF SEVERAL FACTORS ON SAMPLE RECOVERY RATIOS}

The results of grain size distribution tests are summarized in Table 2. Figure 6 also shows the $R_{\mathrm{r}}$ and the grain properties obtained from the SPT sample for borehole No. 3. The Niigata sands tested were medium sand, in which $50 \%$ of the grain size is about $0.25 \mathrm{~mm}$, the percentage of grain size smaller than $0.075 \mathrm{~mm}$ is about $1 \%$, excluding $(4 \sim 7) \%$ of $z=-(8 \sim 10) \mathrm{m}$, and the uniformity coefficient and coefficient of curvature are about 2 and 1 , respectively. Figure 8 shows the relationship between the penetration depth and required penetration time $\left(t_{\mathrm{p}}\right)$ for the 45D, 50D and 70S samplers. The penetration depth and the $t_{\mathrm{p}}$ depend on the samplers used and the rate of penetration was not uniform for items 1 and 2 .

The amounts of pressurized water required $\left(p_{\mathrm{w}}\right)$ for penetration of the sampling tube are shown in Fig. 9 for the 45D, 50D and 70S samplers. This data is shown in sampling depth order. The dashed lines shown for each sampler are the mean values of the $p_{\mathrm{w}}$. The $p_{\mathrm{w}}$ of items 3 and 4 shown for the 45D and 50D samplers in Fig. 9 are about twice those of other data. The items 1 and 2 shown at the $R_{\mathrm{r}}$ plots in Fig. 6 represent a sampling in which the sump was dry and the penetration speed was not uniform as described in Fig. 8. The items 3 and 4 shown at the $R_{\mathrm{r}}$ plots in Fig. 6 represent the partial collapse of samples which is though to have been caused by a decrease in the mud density when water leaked out during tube penetration. It can be judged that the grain properties do not

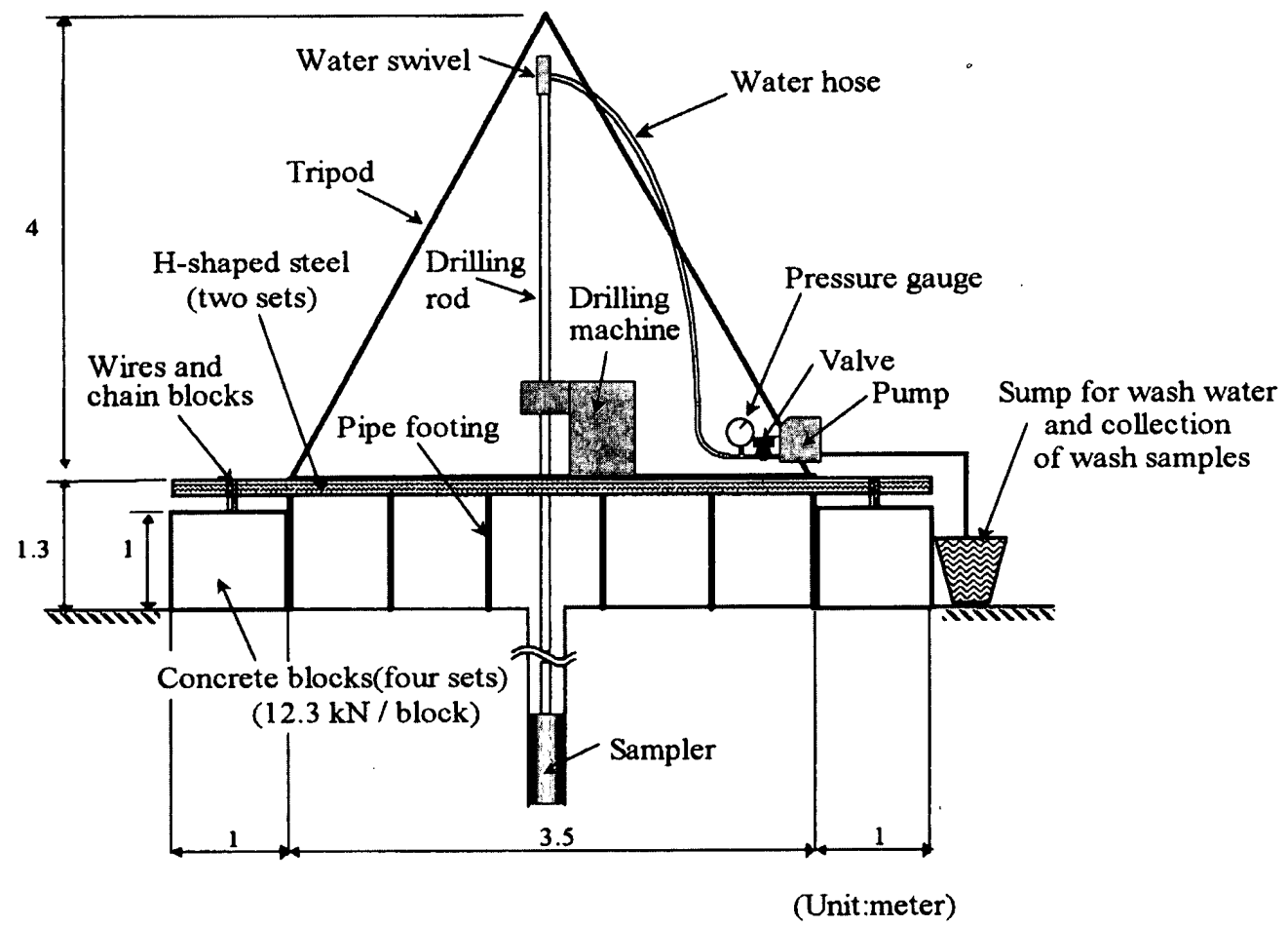

Fig. 5. A sketch of the borer set-up 


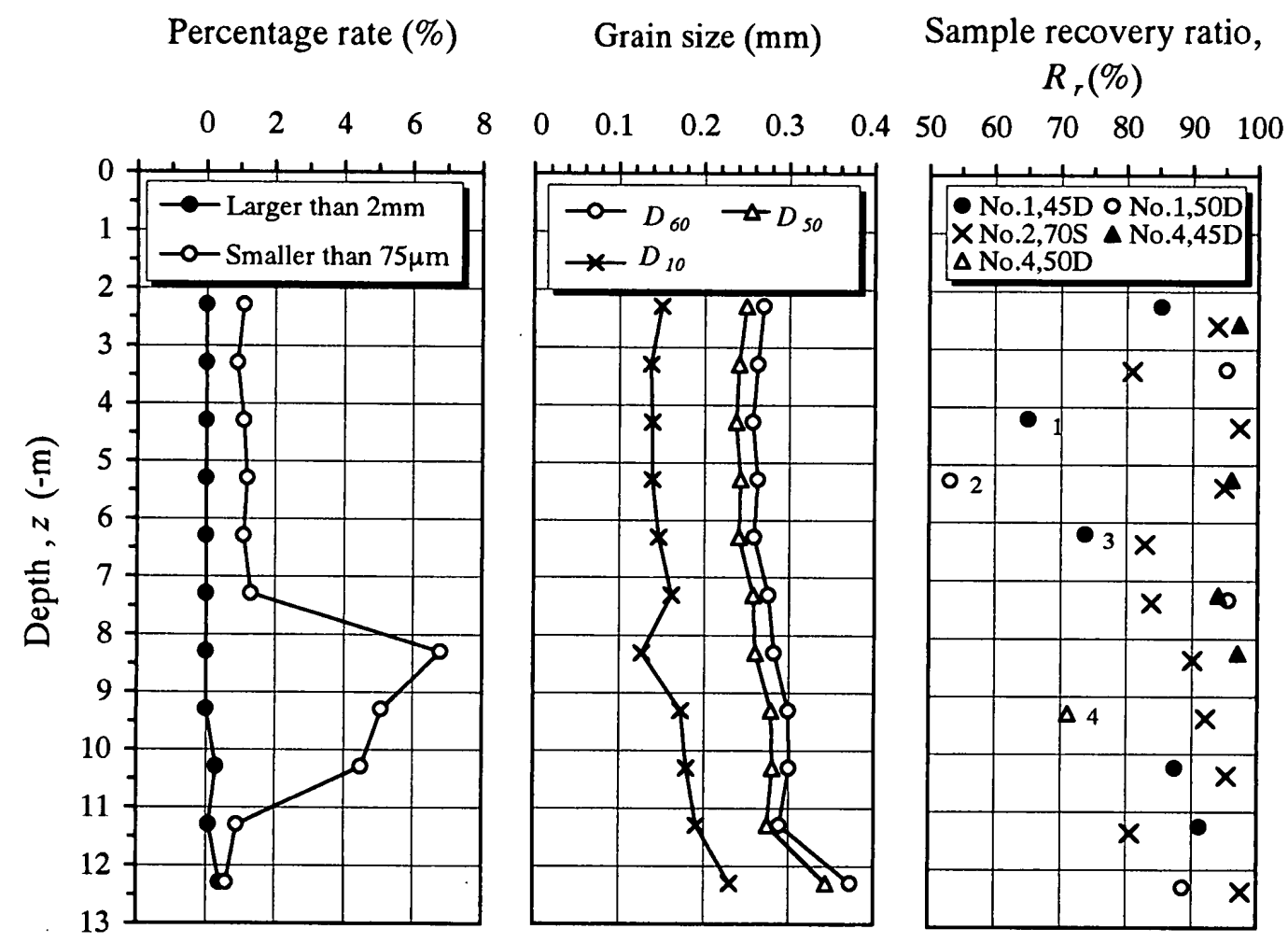

Fig. 6. Sample recovery ratio and the grain properties (No.3 SPT sample)

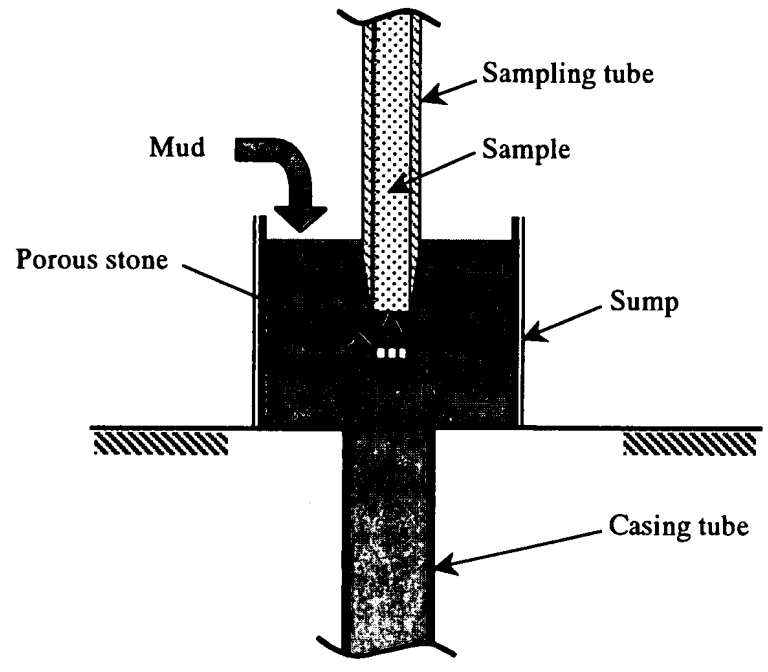

Fig. 7. A sump for mud to avoid sand sample collapse

affect the $R_{\mathrm{r}}$ value since the Niigata sands in this site have almost similar grain properties at varying depths.

Figures 10 and 11 show the relationships between the $R_{\mathrm{r}}$ and $N, q_{\mathrm{c}}$ values, respectively. The $R_{\mathrm{r}}$ values for the plots of 1 through 4 described above are as small as $53 \%$ to $74 \%$, compared to other plots. The $R_{\mathrm{r}}$ values of the 45D and 50D samplers, excluding these plots, are in the range of $85 \%$ to $97 \%$ and the mean value is $93 \%$. The values of the $70 \mathrm{~S}$ sampler are $(81 \sim 97) \%$ and $89 \%$ respectively, and have small values compared with those of the 45D and 50D samplers. These tendencies are independent of $N=3 \sim 54$ and $q_{\mathrm{c}}=2 \sim 26 \mathrm{MPa}$.

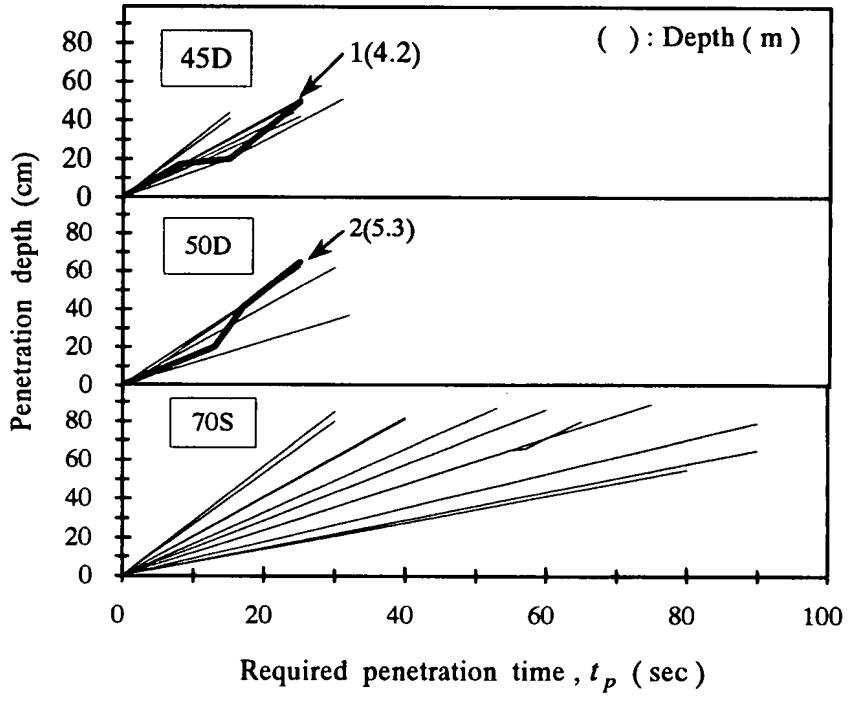

Fig. 8. Relationship between penetration depth and required penetration time

The effect of the mud densities on the $R_{\mathrm{r}}$ values is shown in Fig. 12. When the sampling tube penetrates below the bottom of the borehole, the drilling mud is replaced by new mud having a higher density in order to decrease sample collapse. The mud densities in Fig. 12 are the new densities and were obtained immediately after sampling. The $R_{\mathrm{r}}$ values of the 45D and 50D samplers, excluding the plots of 1 through 4 as shown in Fig. 12, are greater than $85 \%$ and independent of the mud densities having $1.02 \mathrm{~g} / \mathrm{cm}^{3}$ to $1.05 \mathrm{~g} / \mathrm{cm}^{3}$. The straight line in Fig. 12 is a regression line for the plots of the $70 \mathrm{~S}$ sam- 
Table 2. Results of grain size distribution tests

\begin{tabular}{c|c|c|c|c|c|c|c|c|c|c}
\hline Depth (m) & Gravel (\%) & Sand (\%) & Clay and silt (\%) & $D_{\max }(\mathrm{mm})$ & $D_{60}(\mathrm{~mm})$ & $D_{50}(\mathrm{~mm})$ & $D_{30}(\mathrm{~mm})$ & $D_{10}(\mathrm{~mm})$ & $U_{\mathrm{C}}$ & $U_{\mathrm{C}}^{\prime}$ \\
\hline 2.3 & 0.0 & 98.9 & 1.1 & 0.85 & 0.270 & 0.250 & 0.206 & 0.150 & 1.8 & 1.0 \\
\hline 3.3 & 0.0 & 99.1 & 0.9 & 0.85 & 0.263 & 0.241 & 0.195 & 0.138 & 1.9 & 1.0 \\
\hline 4.3 & 0.0 & 98.9 & 1.1 & 0.85 & 0.257 & 0.238 & 0.195 & 0.139 & 1.8 & 1.1 \\
\hline 5.3 & 0.0 & 98.8 & 1.2 & 0.85 & 0.263 & 0.243 & 0.198 & 0.139 & 1.9 & 1.1 \\
\hline 6.3 & 0.0 & 98.9 & 1.1 & 0.85 & 0.259 & 0.241 & 0.202 & 0.147 & 1.8 & 1.1 \\
\hline 7.3 & 0.0 & 98.7 & 1.3 & 0.85 & 0.276 & 0.258 & 0.220 & 0.162 & 1.7 & 1.1 \\
\hline 8.3 & 0.0 & 93.2 & 6.8 & 0.85 & 0.283 & 0.261 & 0.211 & 0.127 & 2.2 & 1.2 \\
\hline 9.3 & 0.0 & 94.9 & 5.1 & 0.85 & 0.300 & 0.279 & 0.237 & 0.173 & 1.7 & 1.1 \\
\hline 10.3 & 0.3 & 95.2 & 4.5 & 4.75 & 0.301 & 0.281 & 0.240 & 0.180 & 1.7 & 1.1 \\
\hline 11.3 & 0.1 & 99.0 & 0.9 & 4.75 & 0.290 & 0.275 & 0.244 & 0.192 & 1.5 & 1.1 \\
\hline 12.3 & 0.4 & 99.0 & 0.6 & 4.75 & 0.373 & 0.344 & 0.292 & 0.231 & 1.6 & 1.0 \\
\hline
\end{tabular}

$D_{\text {max }}:$ Maximum grain size, $D_{60}: 60 \%$ diameter of grain size, $U_{\mathrm{C}}$ : Uniformity coefficient, $U_{\mathrm{C}}^{\prime}:$ Coefficient of curvature

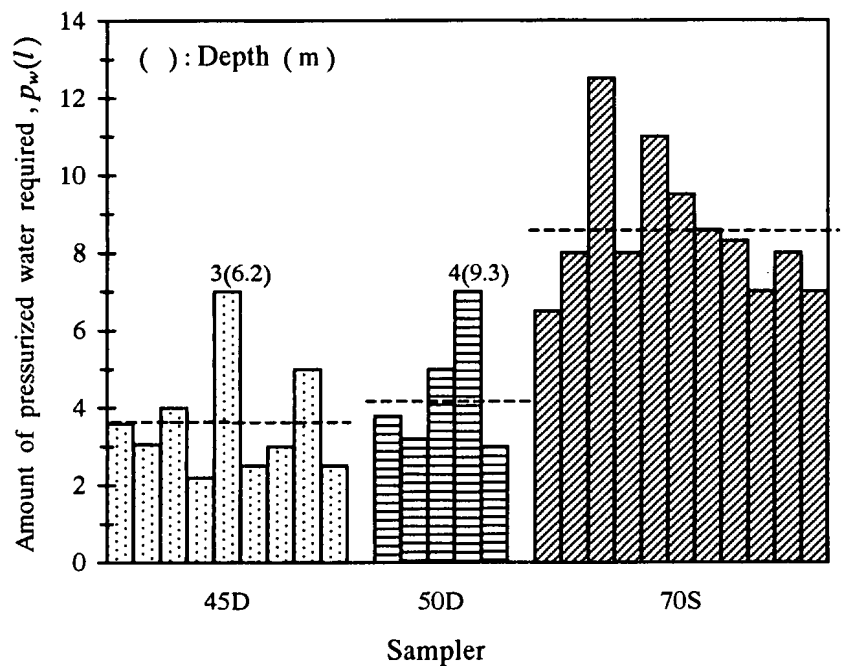

Fig. 9. Relationship between amount of pressurized water required and sampler

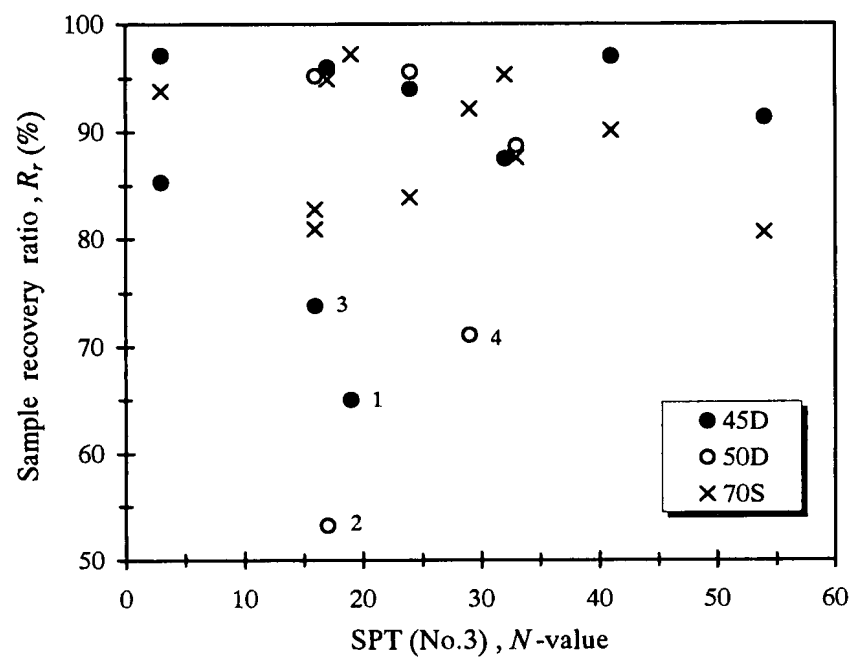

Fig. 10. Relationship between $R_{\mathrm{r}}$ and $N$ values

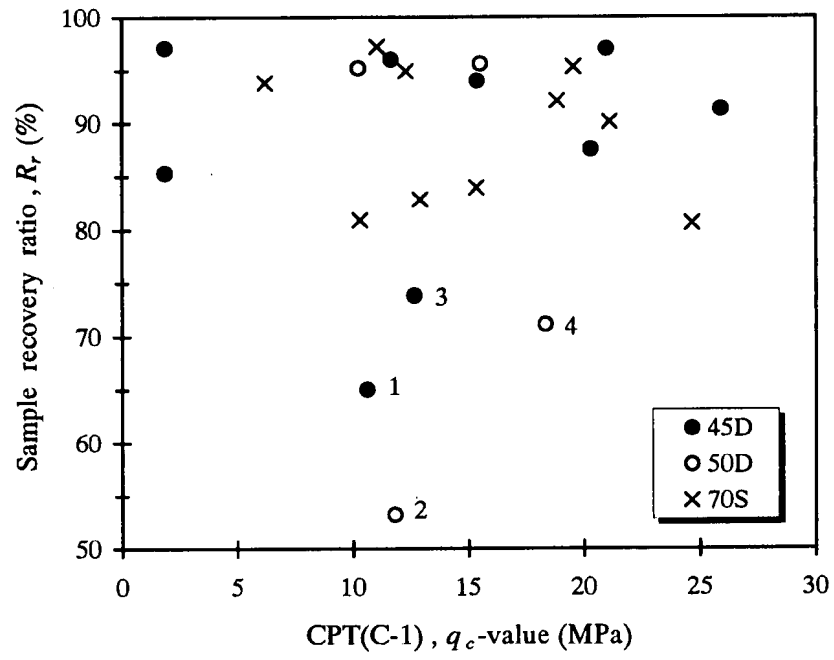

Fig. 11. Relationship between $R_{\mathrm{r}}$ and $q_{\mathrm{c}}$ values

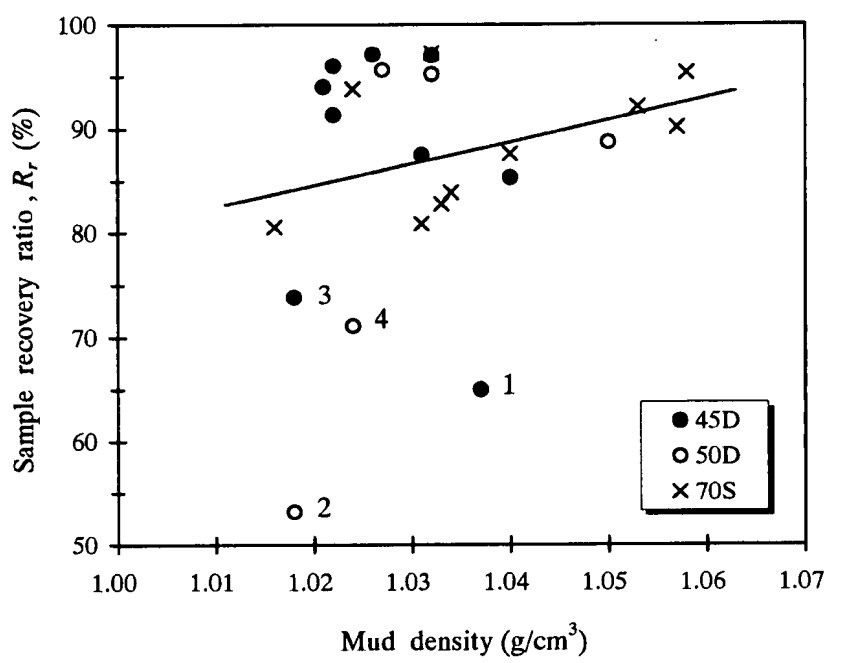

Fig. 12. Relationship between $R_{\mathrm{r}}$ and the mud densities 
Table 3. Sampling methods and samplers as shown in Fig. 13

\begin{tabular}{l|l|l|c}
\hline \multirow{2}{*}{ Investigation } & \multicolumn{2}{|c|}{ Sampling methods and samplers } & Inside diameter of tube (mm) \\
\hline \multirow{4}{*}{ JGS-1989 } & A & Rotary triple-tube sampler & 125 \\
\cline { 2 - 4 } & B & \multirow{2}{*}{ Static penetration-tube sampler } & 50 \\
\cline { 2 - 4 } & C & & 70 \\
\cline { 2 - 4 } & D & Pressure balanced rotary triple-tube sampler & 82 \\
\cline { 2 - 4 } & E & Rotary triple-tube sampler & 83 \\
\cline { 2 - 4 } & F & In-situ freezing method & - \\
\hline Chugonji (2001) & G & Small diameter sampler with a two-chambered hydraulic piston & 50 \\
\hline
\end{tabular}

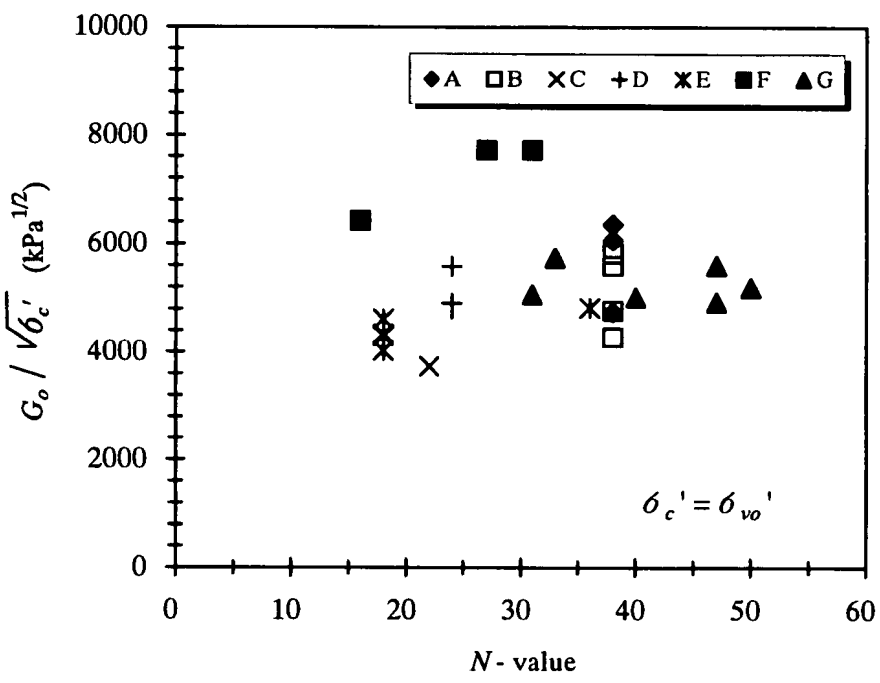

Fig. 13. Relationship between $G_{0} / \sqrt{\sigma_{\mathrm{c}}^{\prime}}$ and $N$ values

pler. Its tendency is that the $R_{\mathrm{r}}$ values of the 70S sampler decrease with a decrease in the mud density caused by its larger diameter, compared to the 45D and 50D samplers. Primarily, it is thought that the sample in the tube collapses easily during the raising of the sampler where the tube inner diameter is larger, since the effect of friction between the tube wall and sand and the arch action decreases with an increasing inner tube diameter. However, this does not indicate a low quality sample. Figure 13 shows the relationship between $G_{0} / \sqrt{\sigma_{c}^{\prime}}$ and $N$ values for Niigata sand, where the $G_{0}$ is initial shear modulus of rigidity, and $\sigma_{\mathrm{c}}^{\prime}$ is effective confining pressure. The test results of the JGS-1989 investigation and the Chugonji site in Niigata city (Nakano et al., 2002) are plotted in Fig. 13. The sands obtained from the Chugonji site are also medium sand, in which $50 \%$ of the grain size is about $0.2 \mathrm{~mm}$, the percentage of grain smaller than $0.075 \mathrm{~mm}$ is less than $5 \%$ and the uniformity coefficient of the sand is 1.6 to 2.0 (Nakano et al., 2002). Both sands have similar grain size distribution and were located on the same sand hill. The sampling methods and samplers as shown in Fig. 13 are listed in Table 3. The $G_{0} / \sqrt{\sigma}^{\prime}$ values of samples obtained from the in-situ freezing method ( $\square$ ) are larger than those of the tube sampling under the same $N$-value. However, the $G_{0} / \sqrt{\sigma_{c}}$ values of

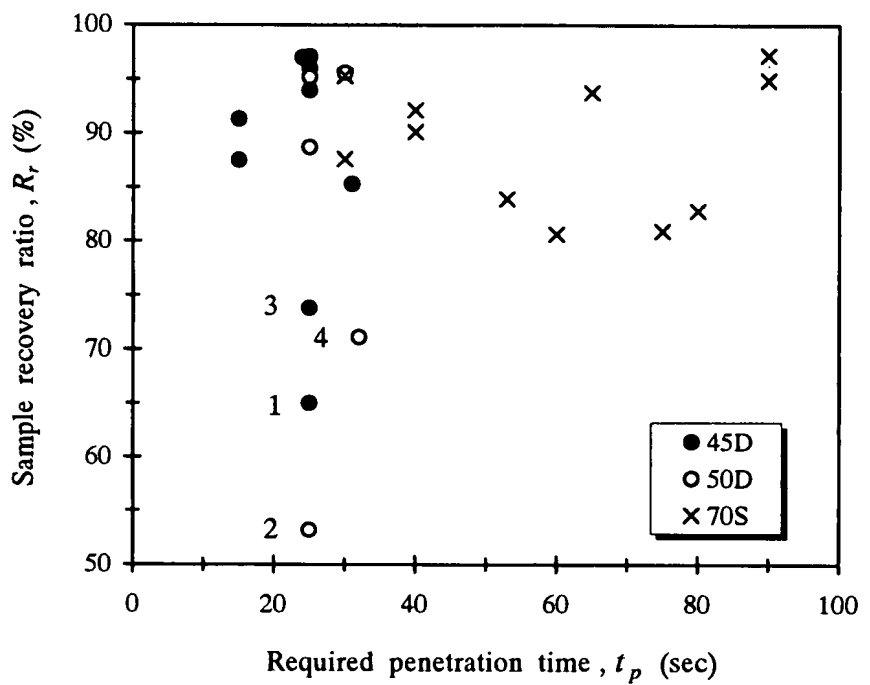

Fig. 14. Relationship between $R_{\mathrm{r}}$ and the required penetration time

samples obtained from the 50D sampler ( $\mathbf{\Delta})$ are almost similar to those of the rotary triple-tube samplers with $125 \mathrm{~mm}(\diamond)$ and $82 \mathrm{~mm} \mathrm{(+)} \mathrm{in} \mathrm{inner} \mathrm{diameter.} \mathrm{The} \mathrm{sam-}$ ple quality is independent of the sampler types and the inner diameter of tubes used in this study. However, special attention should be paid concerning the $R_{\mathrm{r}}$ values of the $70 \mathrm{~S}$ sampler due to changes caused by slight differences in the mud densities.

Figure 14 shows the relationship between the $R_{\mathrm{r}}$ value and the $t_{\mathrm{p}}$. The $t_{\mathrm{p}}$ values are $15 \sim 32$ seconds for the 45D and 50D samplers and 30 90 seconds for the 70S sampler. The maximum sample lengths are $74 \mathrm{~cm}$ and $80 \mathrm{~cm}$ for the 50D and 70S samplers, as shown in Table 1, and have similar values. The shorter $t_{\mathrm{p}}$ values of the 50D sampler are caused by the small diameter tube with a twochambered hydraulic piston. The $R_{\mathrm{r}}$ values are plotted against mean penetration speed $\left(S_{\mathrm{p}}\right)$ in Fig. 15, where the $S_{\mathrm{p}}$ value is defined as the ratio of the tube penetration net depth to the time required for penetration. The largest $S_{\mathrm{p}}$ value is about $3 \mathrm{~cm} / \mathrm{sec}$. The mean $S_{\mathrm{p}}$ values are $2.1 \mathrm{~cm} / \mathrm{sec}$ for the 45D and 50D samples, excluding the plots of 1 through 4 and $1.6 \mathrm{~cm} / \mathrm{sec}$ for the $70 \mathrm{~S}$ sampler. From the smaller $R_{\mathrm{r}}$ value of the 70S sampler, the mean $S_{\mathrm{p}}$ value of the $70 \mathrm{~S}$ sampler is about $30 \%$ smaller than those of the 45D and 50D samplers. 


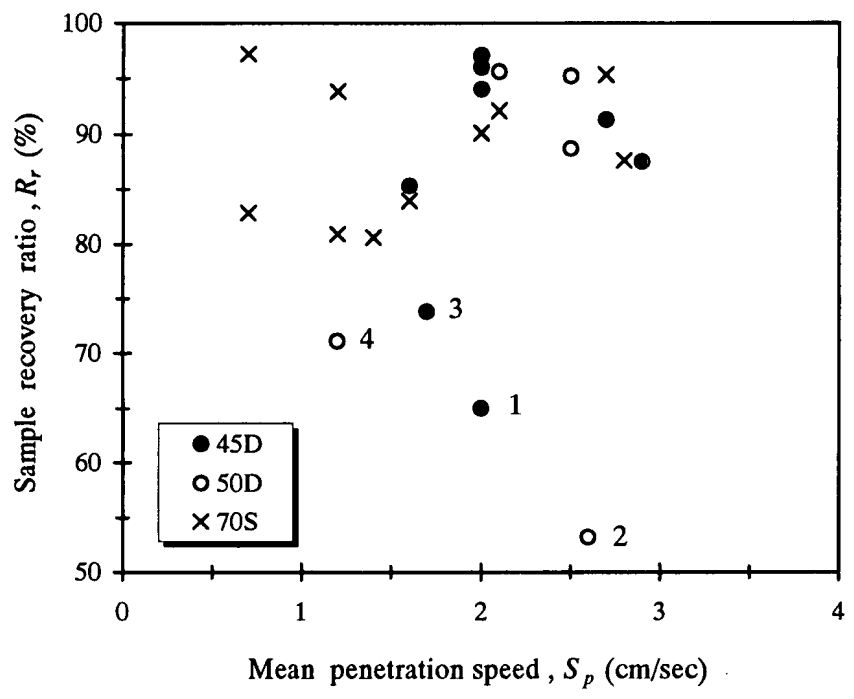

Fig. 15. Relationship between $R_{\mathrm{r}}$ and the mean penetration speed

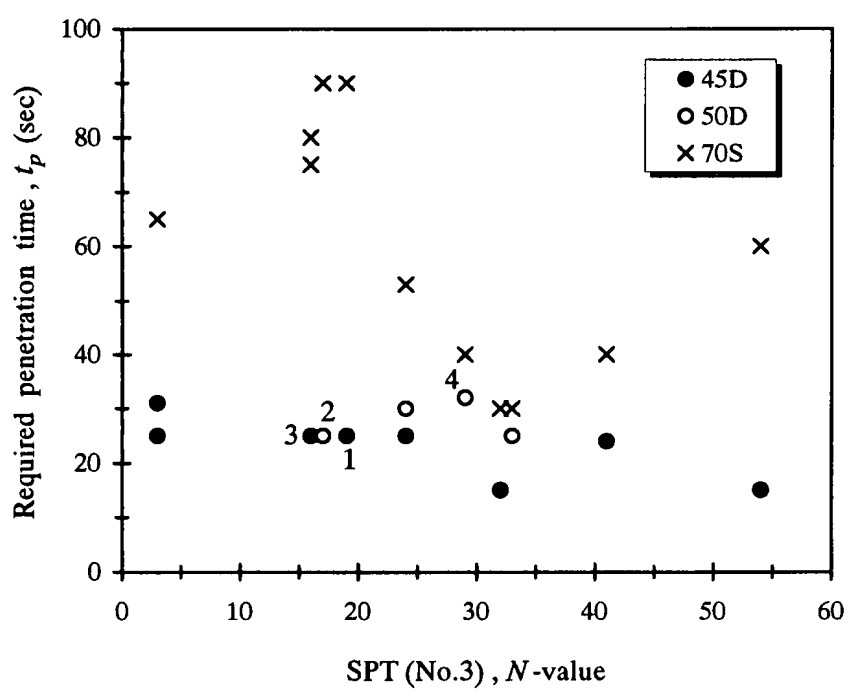

Fig. 16. Relationship between the required penetration time and $N$ values

The relationship between the $t_{\mathrm{p}}$ values, the $S_{\mathrm{p}}$ and $N$ values are shown in Figs. 16 and 17. As shown in Fig. 14, there is a difference in the $t_{\mathrm{p}}$ values between the 70S sampler and both two-chambered hydraulic piston samplers. However, the $t_{\mathrm{p}}$ values are almost constant in the range of $N=3 \sim 54$ for both two-chambered hydraulic piston samplers. The $S_{\mathrm{p}}$ values of each sampler are also independent of the $N$-value.

\section{EFFECT OF SOIL STRENGTH INFLUENCING FLUID PRESSURES AND PENETRATION FORCES OF THE SAMPLERS}

The relationships between the maximum fluid pressures $\left(p_{\max }\right)$ for the tube penetration and the $N$ and $q_{\mathrm{c}}$ values are shown in Figs. 18 and 19. The $p_{\max }$ values increase linearly with the increasing $N$ and $q_{\mathrm{c}}$ values and these tendencies are independent of the sampler types. The straight lines in

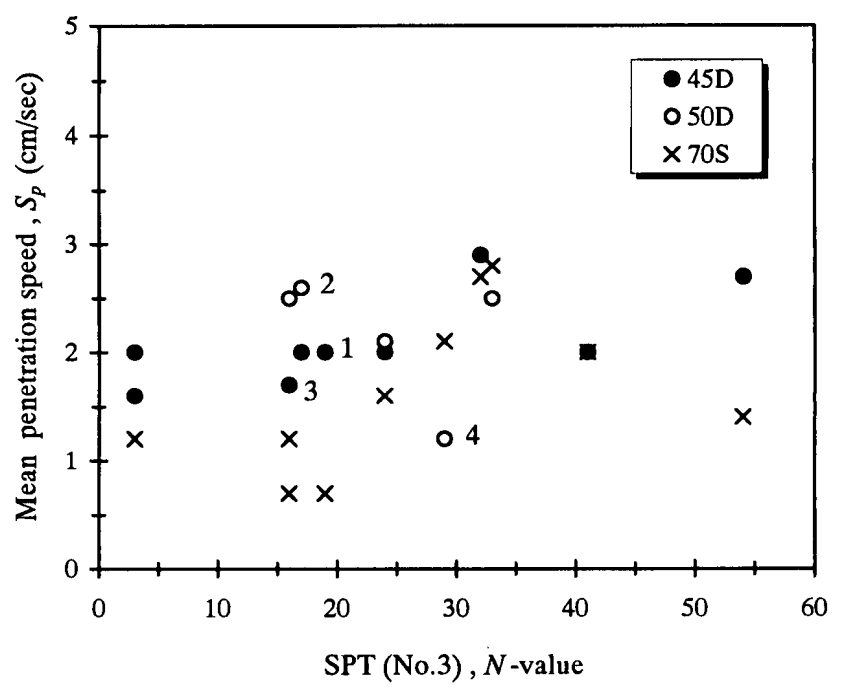

Fig. 17. Relationship between the mean penetration speed and $N$ values

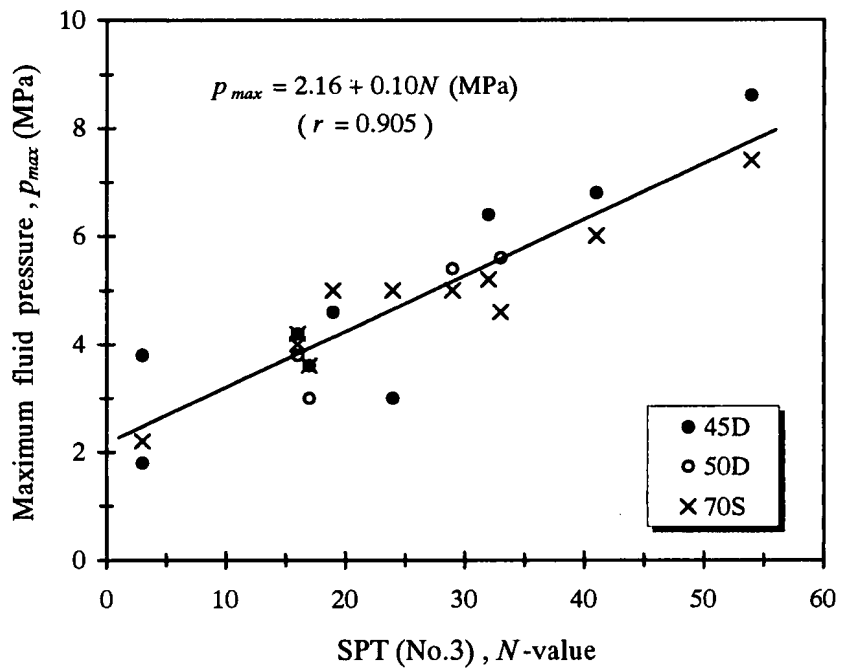

Fig. 18. Relationship between the maximum fluid pressure and $N$ values

Figs. 18 and 19 are regression lines obtained from the least square method and the $p_{\max }$ in $\mathrm{MPa}$ are determined to be $2.16+0.10 N(r=0.905)$ and the $p_{\max }=1.48+0.22 q_{\mathrm{c}}$ $(r=0.864)$. The results of Figs. 18 and 19 can be used for estimating the pump fluid pressure for tube sand sampling.

The relationship between the tube penetration forces $(F)$, which is the $p_{\max }$ values times the total area of a twochambered hydraulic piston, and the $N$-values is shown in Fig. 20. The $F$ values increase linearly with increasing $N$ values independent of sampler types. The straight lines in Fig. 20 are regression lines obtained from the least square method for the $70 \mathrm{~S}$ sampler and the two-chambered hydraulic piston samplers. The $F$ values in $\mathrm{kN}$ are given by $6.62+0.39 N(r=0.903)$ for the 45D and 50D samplers and also given by $11.50+0.42 N(r=0.939)$ for the $70 \mathrm{~S}$ sampler. The $F$ values of the 45D and 50D samplers are $(20 \sim 40) \%$ smaller than those of the $70 \mathrm{~S}$ sampler because 


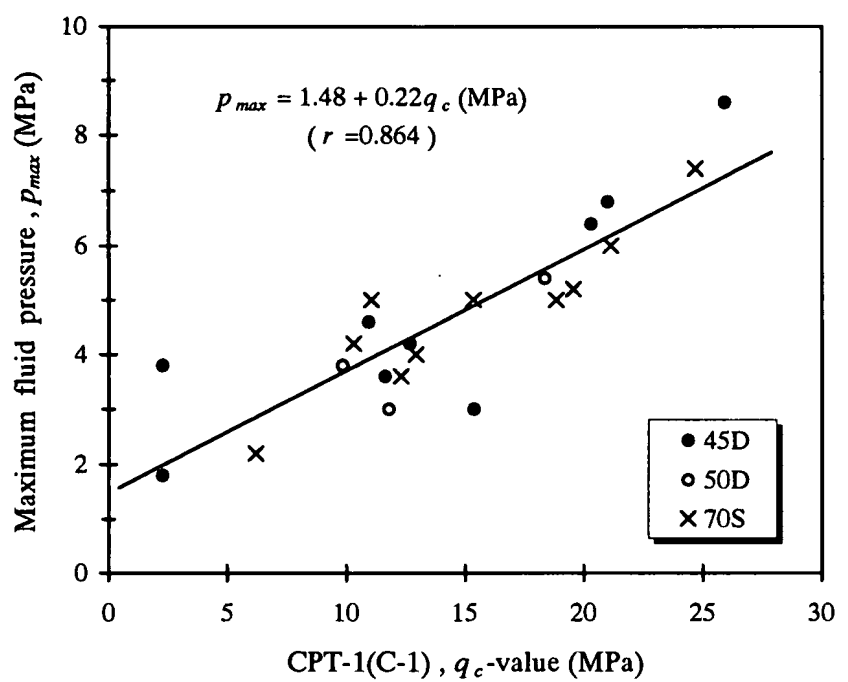

Fig. 19. Relationship between the maximum fluid pressure and $q_{\mathrm{c}}$ values

of the smaller total area. However, the 45D and 50D samplers can sample sands having an $N=53$ value. The result in Fig. 20 can be used for estimating the resistance forces for sampler and drilling equipment penetration because of the $F$ value equivalent of the resistance force.

The effects of sampler types, $R_{\mathrm{r}}, p_{\max }$ and the tube penetration time influencing sample quality will be quantitatively discussed after completing dynamic tests of the soils.

\section{CONCLUSIONS}

The conclusions obtained in this study are summarized as follows:

1) The sample recovery ratios $\left(R_{\mathrm{r}}\right)$ of the $45 \mathrm{D}$ and $50 \mathrm{D}$ samplers were in the range of $85 \%$ to $97 \%$ and the mean value was $93 \%$. The values of the 70 S sampler were $(81 \sim 97) \%$ and $89 \%$, respectively. These tendencies were independent of $N=3 \sim 54$ and $q_{\mathrm{c}}=2 \sim 26$ $\mathrm{MPa}$. However, the $R_{\mathrm{r}}$ values of the 45D and 50D samplers were as small as $53 \%$ to $74 \%$ in situations where there were either, (i) a dry sump, (ii) lower mud densities, or (iii) the penetration speed was not uniform.

2) The $R_{\mathrm{r}}$ values of the 45D and 50D samplers, excluding the above data, were greater than $85 \%$ and independent of the mud densities having $1.02 \mathrm{~g} / \mathrm{cm}^{3}$ to $1.05 \mathrm{~g} / \mathrm{cm}^{3}$. However, the $R_{\mathrm{r}}$ values of the $70 \mathrm{~S}$ sampler decreased with a decrease in the mud density because of its larger diameter. Special attention should be paid concerning the $R_{\mathrm{r}}$ values of the $70 S$ sampler due to the changes caused by slight differences in the mud densities.

3) The maximum fluid pressures $\left(p_{\max }\right)$ for the tube penetration increased linearly with the increasing $N$ and $q_{\mathrm{c}}$ values and these tendencies are independent of the sampler types. The $p_{\max }$ in MPa can be estimated as $2.16+0.10 N$ and the $p_{\max }=1.48+0.22 q_{\mathrm{c}}$. These

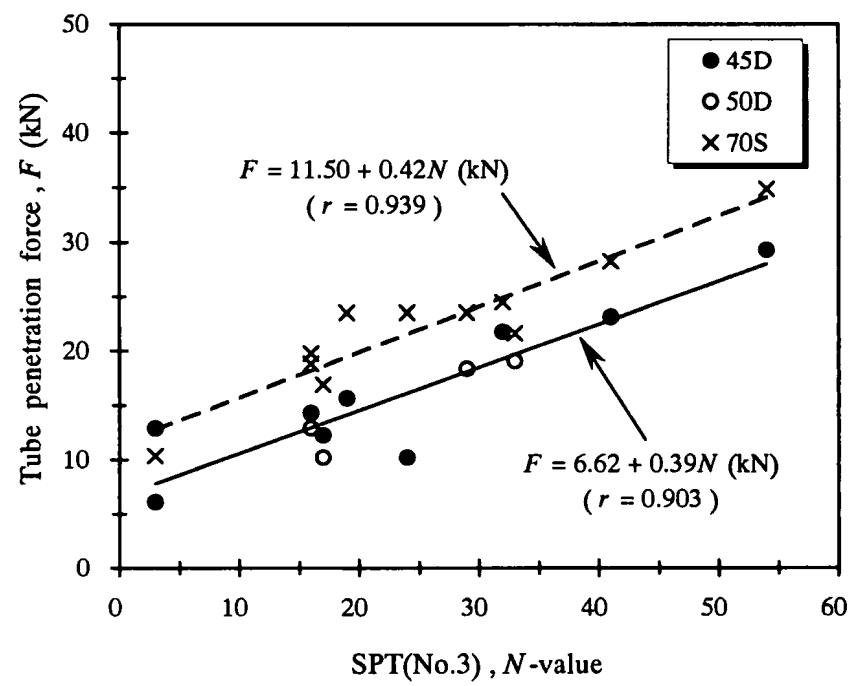

Fig. 20. Relationship between the tube penetration forces and $N$ values

equations can be used for estimating the pump fluid pressure for tube sand sampling since the correlation coefficient $(r)$ of these equations were 0.905 and 0.864 respectively, and are a high value.

4) The tube penetration force $(F)$ values increased linearly with increasing $N$-values independent of sampler types. The $F$ values in $\mathrm{kN}$ were given by $6.62+0.39 N(r=0.903)$ for the 45D and 50D samplers and also given by $11.50+0.42 N(r=0.939)$ for the $70 \mathrm{~S}$ sampler. The $F$ values of the $45 \mathrm{D}$ and 50D samplers were $(20 \sim 40) \%$ smaller than those of the $70 \mathrm{~S}$ sampler because of the smaller total area. However, the 45D and 50D samplers can sample sands having an $N=53$ value. These equations can be used for estimating the resistance forces for sampler and drilling equipment penetration because of the $F$ value equivalent of the resistance force.

\section{ACKNOWLEDGEMENTS}

The authors wish to express their sincere gratitude to the members of the Board of Education of the Niigata City government and the Meike Elementary School for their cooperation in the sampling investigation and also to Professor Kakuichirou Adachi of the Shibaura Institute of Technology and President Yorio Makihara of Arufa Geo. Co. Ltd. for information on the JGS-1989 investigation.

\section{NOTATIONS}

$p_{\mathrm{w}}: \quad$ amount of pressurized water required

$F:$ tube penetration force

$N$ : blow number of the Standard Penetration Test (SPT)

$p_{\max }:$ maximum fluid pressure

$q_{\mathrm{c}}: \quad$ cone index of the Cone Penetration Test (CPT)

$R_{\mathrm{r}}$ : sample recovery ratio

$r$ : correlation coefficient

$S_{\mathrm{p}}$ : mean penetration speed 
$t_{\mathrm{p}}: \quad$ required penetration time

\section{REFERENCES}

1) Japanese Geotechnical Society (1989): A report on the sampling and evaluating sample quality methods for sand deposits, the soil sampling-committee of the Japanese Society for Soil Mechanics and Geotech. Engrg. (in Japanese).

2) Japanese Geotechnical Society (1990): Method for electric cone penetration test (JGS 1435-1995), Soil Testing Methods and Their Explanation, 233-241 (in Japanese).
3) Nakano, Y., Shibata, A. and Shogaki, T. (2002): Dynamic strength and deformation properties of undisturbed Niigata sand using the small diameter sampler with a two-chambered hydraulic piston, 37th JGS Annual Conf., Osaka, 141-142 (in Japanese).

4) Shogaki, T. (1997): A small diameter sampler with a two-chambered hydraulic piston and the quality of its samples, Proc. of the 14th ICSMFE, Hamburg, 201-204.

5) Shogaki, T. and Tokuda, J. (2001): Applicability of a small diameter sampler with a two-chambered hydraulic piston for Japanese clay deposits, Tsuchi-to-Kiso, 49 (4), 12-15 (in Japanese). 